\title{
Identification of tissue of origin in carcinoma of unknown primary with a microarray-based gene expression test
}

\author{
Federico A Monzon ${ }^{1 *}$, Fabiola Medeiros², Maureen Lyons-Weiler', W David Henner ${ }^{3}$
}

\begin{abstract}
Background: Carcinomas of unknown primary (CUP) represent approximately 3\%-5\% of malignant neoplasms. Identifying the tissue of origin (TOO) in these tumors allows for more specific treatment and improves outcomes. However, primary classification remains a challenge in many cases. We evaluated the ability of a microarray-based gene expression test to identify the TOO in tumor specimens from 21 patients with a diagnosis of CUP.

Methods: The Pathwork ${ }^{\circledR}$ TOO Test was used to measure gene expression patterns for 1550 genes; these were compared for similarity to patterns from 15 known tissue types.

Results: The TOO Test yielded a clear single positive call for the primary site in 16 of 21 (76\%) specimens and was indeterminate in 5 (24\%). The positive results were consistent with clinicopathologic suggestions in 10 of the 16 cases (62\%). In the remaining six cases the positive results were considered plausible based on clinical information. Positive calls included colorectal (5), breast (4), ovarian (3), lung (2), and pancreas (2). The TOO Test ruled out an average of 11 primary tissues in each CUP specimen.
\end{abstract}

Conclusion: The Pathwork TOO Test reduced diagnostic uncertainty in all CUP cases and could be a valuable addition or alternative to current diagnostic methods for classifying uncertain primary cancers.

\section{Background}

Patients with carcinoma of unknown primary (CUP) present with metastatic disease for which the tissue of origin (TOO) cannot be identified. About $3 \%-5 \%$ of all diagnosed cancers are classified as CUP [1-4] and an estimated 31,490 new cases of cancer of unspecified primary sites were diagnosed in the United States in 2008 [5]. Prognosis of patients with CUP is usually poor with empiric treatment. Median survival is 3-9 months even with newer combination regimens [4,6-10]. It has been shown that survival can improve if the primary site is identified and specific therapy is instituted $[11,12]$ as currently recommended in therapeutic guidelines $[4,13]$.

Unfortunately, primary tumor detection remains challenging. While serum tumor markers, imaging tests, and immunohistochemistry (IHC) panels can help identify the tissue of origin, the primary site is identified in

\footnotetext{
* Correspondence: FAMonzon@tmhs.org

'Clinical Genomics Facility, University of Pittsburgh, Pittsburgh, Pennsylvania, USA
}

\section{Biomed Central}

fewer than $30 \%$ of those who present initially with occult primary tumor [13-15]. Furthermore, some positive findings can be misleading $[2,16]$. For example, in three large IHC studies ( $>50$ specimens) of known metastatic specimens, IHC findings failed to agree with the site of origin in about one third of cases [17-19]. In addition, CUP diagnostic workups today are all too often time-consuming, expensive, and unsuccessful $[13,20]$.

Recently, gene expression tests to classify tumors by tissue origin have been developed. These tests employ microarrays or real-time reverse transcriptase polymerase chain reaction (RT-PCR) to measure mRNA transcripts [21-29] and one uses a microarray to quantify microRNAs [30]. Thus far, performance of these expression tests has been assessed mainly by challenges against panels of tumors from known primary sites; however, the panel composition has varied widely in terms of specimen number, specimen handling, tissue types included, number of replicates for each tissue type, and the proportions of metastatic and poorly differentiated 
tumors. Overall, the accuracy in these studies has been in the range of $76 \%$ to $89 \%$. Although these performance studies are necessary and important, a challenge with actual CUP specimens is needed to gauge the true clinical value of these tests. Designing such a study is inherently difficult because CUP specimens, by definition, lack a reference diagnosis. Only recently have expression-based tissue test results in CUP specimens been reported [31-33].

The Pathwork ${ }^{\circ}$ TOO Test (Pathwork Diagnostics, Sunnyvale, California, U.S.) is a microarray-based gene expression diagnostic test for determining the similarity of a tumor specimen to 15 known tissue types. The test interprets the expression of 1550 genes in each specimen by applying normalization and classification algorithms to gene expression data from a microarray. The similarity of each tumor specimen's gene expression pattern is compared to the 15 tissues covered by the test. For each specimen, the pathologist receives a report with 15 separate scores that reflect the similarity of the specimen's gene expression profile to each of the reference tissues. Evaluation of the TOO Test found highly reproducible results across four laboratories [28] and in a blinded multicenter evaluation of 547 known primaries (47\% metastatic, $53 \%$ poorly differentiated or undifferentiated primaries), the test had an overall agreement of $87.8 \%$ with the pathologist-issued diagnosis [29].

In this study, we evaluated the clinical utility of the TOO Test in identifying the primary site in specimens from patients diagnosed with CUP. The aims were to evaluate the test's ability to issue a clear positive call in classic CUP specimens, to check the consistency of the test results against a short-list of diagnostic possibilities based on clinicopathology, and to estimate the potential added clinical value of positive and negative results in guiding management.

\section{Methods}

\section{Study Design}

This was a retrospective study of tumor specimens from 21 patients diagnosed with CUP. Fresh-frozen specimens were obtained from tissue banks at the Mayo Clinic and the University of Pittsburgh. The specimens had been archived between January 1998 and December 2006. Specimen processing and microarray scanning were performed at each site. Data files were analyzed by Pathwork Diagnostics and a report was generated. Electronic test scores were sent to study site pathologists who were blinded to the associated patient's clinicopathologic information. The pathologists used predetermined cutoffs to make final expression test calls of positive or indeterminate for each specimen. The code was then broken and expression results were compared with the available clinical, radiologic, pathological, and therapeutic findings as a basis for conclusions about the consistency, plausibility, and potential added clinical value of TOO Test results. The study was conducted under protocols approved by the institutional review boards of each institution.

\section{Case Selection and CUP Definition}

Cases were first identified for possible inclusion in the study by manual and electronic searching of tissue bank archives. Search terms and diagnostic codes included "CUP," "unknown," and "uncertain." Specimens with a high number of IHC results were also selected for review.

Most patients whose specimens were included had received a complete history, physical, and full clinical, laboratory, imaging, and pathologic workups, including standard histologic and IHC examination, prior to their designation as CUP. Specimens from patients from the Mayo Clinic $(n=11)$ were also evaluated by a panel of stains to rule out certain subsets of malignancies. These stains included but were not limited to: keratins or epithelial membrane antigen, S-100 or HMB45, LCA (CD45), chromogranin or synaptophysin, CK20, CK7, thyroid transcription factor 1 (TTF-1), and CDX-2. Directed evaluation of symptomatic areas and targeted testing based on history or symptoms (e.g., abdominal CT, mammogram in women, colonoscopy in cases of liver metastasis) were undertaken in Mayo Clinic patients. Specimens designated as biopsy-proven carcinomas (e.g., carcinomas, adenocarcinomas, and mucinous adenocarcinomas) with varying levels of differentiation and from various sites were included. Available treatment data and performance status for Mayo Clinic patients were compiled but not required for inclusion.

The minimum inclusion criteria for screened specimens were: (1) characterization as CUP after well-documented pathologic examination; (2) availability of frozen specimen block with histologic verification of at least $60 \%$ tumor representation and less than $20 \%$ necrosis; (3) availability of medical records with core demographics as well as a clinicopathologic report including a summary of any narrowed diagnostic possibilities. Any specimens assigned a definitive single tissue type or included in previous studies reporting performance of the TOO Test $[28,29]$ were excluded.

\section{Gene Expression Test}

The study pathologist at each site checked necrosis and tissue viability in a section from each frozen tissue block and then RNA was extracted and processed according to previously published methods [28]. Spectrophotometry was used to assess adequate total RNA concentration and purity. In general, the protocol for processing the RNA, amplifying and labeling fragments, hybridizing material on the microarray, and scanning is similar to the standard Affymetrix protocol for 3'-based gene 
expression analysis. Both laboratories used the proprietary Pathwork Pathchip ${ }^{\mathrm{Tm}}$ or an Affymetrix GeneChip array on Affymetrix 3000 or 3000Dx GeneChip instrumentation (fluidics station and scanner) and the GeneChip operating software to generate gene expression data (.CEL files). Raw data files were submitted to Pathwork Diagnostics for automated analysis and report generation (Figure 1).

The Pathwork TOO Test algorithm transforms probelevel intensity data into gene expression values, performs data verification, and standardizes expression values

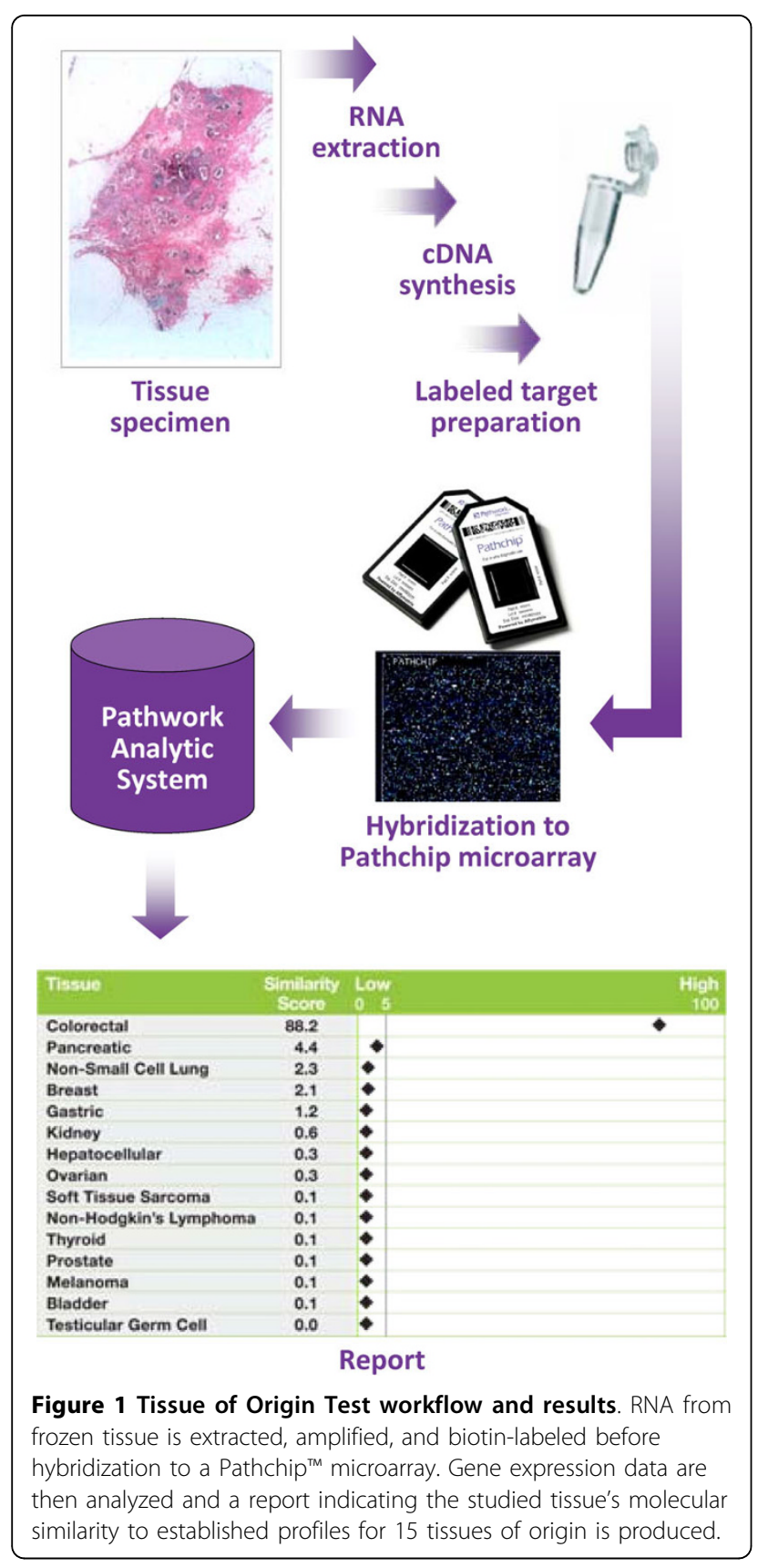

using a 121-gene standardization method whose performance has been previously described [28,34]. Expression levels of the 1550 genes for each specimen are then compared in pairwise fashion with the pre-established gene profiles for each of the 15 tissues on the test panel. The results are presented on an electronic report as 15 separate Similarity Scores (SS), one for each tissue on the panel.

\section{Data Analysis}

Coded electronic reports with SS and no patient information were sent to investigators, who used pre-established cutoffs to make a final determination about each tissue type as positive or indeterminate. The SS for each of the 15 tissue types ranged from 0 (very low similarity) to 100 (very high similarity). Per cut-offs determined before the study, a SS of 30 or above indicated the presence of a given tissue in the specimen, a SS of 5 or less indicated the absence of a given tissue in the specimen, and a SS between 5 and 30 was considered indeterminate $[28,29]$.

For each specimen, the final TOO Test result was compared with available clinical, laboratory, and imaging results for that specimen and a determination was made about the overall consistency of the TOO Test positive result with the clinicopathologic suggestions. Given the challenging nature of CUPs, inconsistencies were expected. In some inconsistent cases, investigators evaluated the plausibility of TOO Test results by re-examining the patient file and, in some cases, performing additional IHC analysis (CDX2 stain in two cases). Investigators also performed a case-by-case review to determine the consistency of negative tissue calls with the clinicopathologic suggestion.

\section{Results}

\section{Patient and Tumor Characteristics}

Characteristics for individual patients from Mayo $(\mathrm{n}=11)$ and the University of Pittsburgh $(n=10)$ are detailed in Table 1. Most patients were in the age range of 60-69 $(n=6)$ or 70-79 years of age $(n=7)$. The majority of patients (15 of 21 ) were female. Tumor specimens were taken from over a dozen different biopsy sites. Most cases were described as having a stage IV or metastatic tumor. Most specimens were characterized morphologically as poorly differentiated $(\mathrm{n}=13)$ or moderately differentiated ( $\mathrm{n}=7)$.

\section{Tumor IHC Analysis}

A total of 49 unique IHC markers were employed in an attempt to identify the origin of the tissue in these 21 specimens. An average of six IHC tests were performed on each specimen (range: 0 to 13) and 12 of the 21 specimens received at least seven different IHC staining tests including those targeting proteins known to be useful in predicting tissue type (e.g., CK7, CK20, ER, 
Table 1 Patient characteristics

\begin{tabular}{|c|c|c|c|c|c|c|}
\hline $\begin{array}{l}\text { Case } \\
\text { No. }\end{array}$ & Age & Gender & Biopsy site & $\begin{array}{l}\text { Prior cancer } \\
\text { history }\end{array}$ & Morphology & CUP treatment regimen \\
\hline 1 & $70-79$ & $\mathrm{~F}$ & Liver & Breast & Moderately-differentiated adenocarcinoma & supportive care only \\
\hline 2 & $70-79$ & M & Mesentery & None & Poorly-differentiated adenocarcinoma & supportive care only \\
\hline 3 & $60-69$ & $\mathrm{~F}$ & Soft Tissue & Breast & Poorly-differentiated carcinoma & supportive care only \\
\hline 4 & $50-59$ & $\mathrm{~F}$ & Peritoneum & None & Poorly-differentiated adenocarcinoma & $\begin{array}{l}\text { paclitaxel/carboplatin/ } \\
\text { gemcitabine }\end{array}$ \\
\hline 5 & $80-89$ & $\mathrm{~F}$ & Bone & Breast & Poorly-differentiated carcinoma & radiation \\
\hline 6 & $80-89$ & $\mathrm{~F}$ & Soft tissue & None & Moderately-differentiated carcinoma & supportive care only \\
\hline 7 & $80-89$ & M & Pleura & $\begin{array}{l}\text { Prostate, } \\
\text { Bladder }\end{array}$ & Moderately-differentiated adenocarcinoma & supportive care only \\
\hline 8 & $60-69$ & $\mathrm{~F}$ & Peritoneum & None & Poorly-differentiated carcinoma & paclitaxel/carboplatin \\
\hline 9 & $70-79$ & $\mathrm{~F}$ & Peritoneum & Rectal & Poorly-differentiated carcinoma & supportive care only \\
\hline 10 & $50-59$ & $\mathrm{~F}$ & Peritoneum & Ovarian & Well-differentiated mucinous adenocarcinoma & supportive care only \\
\hline 11 & $60-69$ & $\mathrm{~F}$ & Peritoneum & Breast & Poorly-differentiated carcinoma & paclitaxel/carboplatin \\
\hline 12 & $50-59$ & $\mathrm{~F}$ & Right Femur & N/A & $\begin{array}{l}\text { Metastatic, well-to- moderately differentiated } \\
\text { adenocarcinoma }\end{array}$ & $\mathrm{N} / \mathrm{A}$ \\
\hline 13 & $50-59$ & $\mathrm{~F}$ & Left Femur & N/A & Metastatic, poorly-differentiated adenocarcinoma & $\mathrm{N} / \mathrm{A}$ \\
\hline 14 & 70-79 & $\mathrm{F}$ & Lymph Node & $\mathrm{N} / \mathrm{A}$ & Metastatic poorly-differentiated adenocarcinoma & $\mathrm{N} / \mathrm{A}$ \\
\hline 15 & $70-79$ & $\mathrm{~F}$ & $\begin{array}{l}\text { Lung (Upper } \\
\text { Lobe) }\end{array}$ & N/A & Moderately-differentiated papillary adenocarcinoma & $\mathrm{N} / \mathrm{A}$ \\
\hline 16 & $60-69$ & $\mathrm{~F}$ & Omentum & $\mathrm{N} / \mathrm{A}$ & Metastatic poorly-differentiated adenocarcinoma & $\mathrm{N} / \mathrm{A}$ \\
\hline 17 & $70-79$ & M & Abdominal Wall & N/A & Metastatic poorly-differentiated adenocarcinoma & $\mathrm{N} / \mathrm{A}$ \\
\hline 18 & $70-79$ & M & Right Groin & N/A & Metastatic adenocarcinoma & $\mathrm{N} / \mathrm{A}$ \\
\hline 19 & $40-49$ & M & Colon/Omentum & N/A & Poorly-differentiated adenocarcinoma & N/A \\
\hline 20 & $60-69$ & M & Right Clavicle & N/A & Moderately-differentiated mucinous adenocarcinoma & N/A \\
\hline 21 & $60-69$ & $F$ & $\begin{array}{l}\text { Liver/Lymph } \\
\text { Node }\end{array}$ & N/A & $\begin{array}{l}\text { Liver: poorly-differentiated carcinoma } \\
\text { LN: metastatic poorly-differentiated carcinoma }\end{array}$ & $\mathrm{N} / \mathrm{A}$ \\
\hline
\end{tabular}

N/A = not available

PSA, TTF-1) [18,19]. Results of IHC analyses are listed in Table 2.

\section{TOO Test Results}

The Pathwork TOO Test gave a positive result for a single tissue in 16 (76\%) of 21 CUP specimens (Table 2). The identified primary sites included colorectal (5), breast (4), ovary (3), lung (2), and pancreas (2). The TOO Test was indeterminate in five cases (24\%) (Figure 2 ). The average SS in positive calls was 66.4 while the average highest SS in indeterminate calls was 23.0.

The TOO Test positive results were consistent with clinicopathologic suggestions in 10 of the 16 cases (62\%). For example, in Case 3 the TOO Test yielded a positive ovarian call, thus confirming one of the two main tissues types under consideration (breast vs. ovarian). In Case 4, the TOO Test pointed to a colorectal origin while the pre-existing clinicopathologic data (based on colonoscopy, mammogram, abdominal CT, and 10 IHC stains) hinted at, but did not confirm, a gastrointestinal (GI) origin. In five of seven specimens called positive for GI origin (5 colorectal, 2 pancreas), the TOO Test result was not unexpected given the pre-existing clinical differential.
Overall, six cases of unexpected positive TOO Test results were produced. There were no obvious instances of TOO Test error or high unlikelihood based on all existing patient information (e.g., a prostate call in a female patient, a sarcoma or melanoma call for a histologically confirmed adenocarcinoma). Also, in many cases, tissue types under active consideration were "ruled out" based on negative results in expression testing. In Case 6, for example, where the patient was strongly suspected of having either a primary lung or thyroid carcinoma due to positive TTF-1 staining, the TOO Test result of breast carcinoma, while unexpected, had not been absolutely ruled out by clinical factors. Importantly, TTF-1 positivity has been reported in a small percentage of breast and colon carcinomas $[35,36]$. Further, the TOO Test gave negative Similarity Scores for both lung $(\mathrm{SS}=3.8$ ) and thyroid $(\mathrm{SS}=1.1$ ). Similarly, in Case 2 a diagnosis of renal cell carcinoma was originally suspected but the TOO Test call of colorectal carcinoma was not improbable and the TOO Test also provided a negative kidney signal $(S S=0.6)$. Immunostain for CDX2 performed during this study and not 
Table 2 Immunohistochemical and Tissue of Origin Test results

\begin{tabular}{|c|c|c|c|c|c|c|c|c|}
\hline \multicolumn{4}{|c|}{ Immunohistochemistry Results } & \multicolumn{5}{|c|}{ Tissue of Origin (TOO) Test results } \\
\hline $\begin{array}{l}\text { Case } \\
\text { No. }\end{array}$ & Negative & Positive & $\begin{array}{l}\text { Suspected tissues } \\
\text { based on } \\
\text { clinicopathology }\end{array}$ & TOO result & $\begin{array}{l}\text { TOO } \\
\text { SS }\end{array}$ & $\begin{array}{l}\text { Rule } \\
\text { out } \\
\text { tissues }\end{array}$ & Consistent & $\begin{array}{c}\text { Management } \\
\text { Value }\end{array}$ \\
\hline 1 & $\begin{array}{l}\text { BRST-2, CK20, TTF-1, ER, } \\
\text { PR, Her2/neu }\end{array}$ & CK7 & $\begin{array}{l}\text { Pancreas, Breast, } \\
\text { Upper Gl }\end{array}$ & Indeterminate & 22.1 & 8 & - & - \\
\hline 2 & PSA & CK20, CK7, CDX2* & Kidney & Colorectal & 83.7 & 14 & $\mathrm{No}^{*}$ & Yes \\
\hline 3 & $\begin{array}{l}\text { BRST-2, CK20, TTF-1, ER, } \\
\text { PR, Her2/neu }\end{array}$ & CK20, CK7, WT1 & Ovary or Breast & Ovary & 87.6 & 14 & Yes & Yes \\
\hline 4 & $\begin{array}{l}\text { chromogranin, } \\
\text { synaptophysin, calretinin, } \\
\text { TTF-1, PR }\end{array}$ & $\begin{array}{l}\text { CK20, CK7, CDX-2, CK5/6, } \\
\text { MOC31, ER, CEA }\end{array}$ & $\begin{array}{l}\text { Gl Primary, } \\
\text { Colorectal }\end{array}$ & Colorectal & 81.8 & 13 & Yes & Yes \\
\hline 5 & $\begin{array}{l}\text { CDX-2, CD31, CK20, } \\
\text { Melan A, S-100, TTF-1 }\end{array}$ & AE1/AE3, CK7 & Renal cell carcinoma & Indeterminate & 24.7 & 11 & - & - \\
\hline 6 & Thyroglobulin & TTF-1 & Lung, Thyroid & Breast & 61.2 & 12 & $\mathrm{No}^{*}$ & Yes \\
\hline 7 & CK20, PSA, TTF-1 & $\begin{array}{l}\text { CK7, AE1/AE3, keratin } \\
\text { 903, p63 }\end{array}$ & Lung & Indeterminate & 23.6 & 8 & - & \\
\hline 8 & BRST-2, CD10, CD45, C-kit & $\begin{array}{l}\text { CDX-2, CAM5.2, CK20, } \\
\text { CK7, Keratin }\end{array}$ & Colorectal & Colorectal & 64.1 & 12 & Yes & Yes \\
\hline 9 & CK20, CK7, TTF-1, ER, PR & & Colorectal, Ovary & Lung & 35.5 & 10 & $\mathrm{No}^{*}$ & Yes \\
\hline 10 & & CDX-2* ${ }^{*}$ CK20, CK7 & Colorectal, Ovary & Colorectal & 71.2 & 13 & Yes & Yes \\
\hline 11 & $\begin{array}{l}\text { ER, PR, Her2/neu, BRST-2, } \\
\text { CDX-2, CK20 }\end{array}$ & CK7, p53, WT1 & Breast, Ovary & Ovarian & 86.6 & 14 & Yes & Yes \\
\hline 12 & $\begin{array}{l}\text { chromogranin, } \\
\text { synaptophysin, surfactant, } \\
\text { TTF, CK20, LCA, CA-125, } \\
\text { Her2/neu }\end{array}$ & $\begin{array}{l}\text { ER, PR, monoclonal CEA, } \\
\text { focal CK7 }\end{array}$ & Breast, Ovary, Uterine & Breast & 96.4 & 14 & Yes & Yes \\
\hline 13 & Her2/neu, PR & $\begin{array}{l}\text { estrogen receptor }(10 \% \\
\text { cells staining at } 1+)\end{array}$ & Breast & Breast & 95 & 14 & Yes & Yes \\
\hline 14 & $\begin{array}{l}\text { HMB45, Tyrosinase, } \\
\text { Melan-A, RCC, ER }\end{array}$ & $\begin{array}{l}\text { CK7, AE1/AE3, CAM 5.2, } \\
\text { TTF, S100, surfactant } \\
\text { protein, CK20; weak } \\
\text { CDX-2 }\end{array}$ & Lung & Ovarian & 87.5 & 13 & $\mathrm{No}^{*}$ & Yes \\
\hline 15 & & EGF-R & Lung & Lung & 66.9 & 12 & Yes & Yes \\
\hline 16 & LeuM1, S100 & $\begin{array}{l}\text { PLAP, CA-125, } \\
\text { monoclonal CEA }\end{array}$ & Pancreas, Ovary & Pancreas & 39.5 & 11 & Yes & Yes \\
\hline 17 & $\begin{array}{l}\text { PSA, neuroendocrine } \\
\text { markers, S100 }\end{array}$ & $\begin{array}{l}\text { mucicarmine, CEA, } \\
\text { cytokeratin }\end{array}$ & $\begin{array}{l}\text { Colon, Prostate, } \\
\text { Stomach, Lung }\end{array}$ & Pancreas & 37.3 & 10 & $\mathrm{No}^{*}$ & Yes \\
\hline 18 & $\begin{array}{l}\text { PSA, TTF, calretinin, } \\
\text { thrombomodulin, P63 }\end{array}$ & $\begin{array}{l}\text { CK7, CK20, monoclonal } \\
\text { CEA, CDX-2 }\end{array}$ & $\begin{array}{l}\text { Esophagus, Stomach, } \\
\text { Pancreas, Biliary }\end{array}$ & Breast & 36.1 & 10 & $\mathrm{No}^{*}$ & Yes \\
\hline 19 & $\begin{array}{l}\text { smooth myo actin, } \\
\text { desmin, S100, HMB-45, } \\
\text { CD34, chromogranin, CK7 }\end{array}$ & $\begin{array}{l}\text { focal C-kit, focal } \\
\text { synaptophysin, focal } \\
\text { CK20, mucicarmine, PAS }\end{array}$ & Colon & Colorectal & 31.5 & 8 & Yes & Yes \\
\hline 20 & Not available & Not available & None & Indeterminate & 24 & 9 & - & - \\
\hline 21 & $\begin{array}{l}\text { mucicarmine, HepPar, } \\
\text { alpha-fetoprotein, } \\
\text { synaptophysin }\end{array}$ & $\begin{array}{l}\text { CEA monoclonal/ } \\
\text { polyclonal, Cam-5.2, AE1 }\end{array}$ & $\begin{array}{l}\text { Liver, } \\
\text { Cholangiocarcinoma }\end{array}$ & Indeterminate & 20.7 & 9 & - & - \\
\hline
\end{tabular}

* Still a plausible primary call given the overall patient presentation and clinicopathologic findings; see text for discussion.

SS: Similarity Score; AE: cytokeratin; BRST: Breast; C-kit: cytokine receptor CD117; CA-125: cancer antigen 125; Cam 5.2: anti-cytokeratin; CD: cluster of differentiation; CDX: an intestine-specific transcription factor; CEA: carcinoembryonic antigen; CK: cytokeratin; ER: estrogen receptor; HepPar: hepatocyte paraffin; Her-2/neu: human epidermal growth factor receptor 2; HMB-45: human melanoma black; LeuM1: a granulocyte-related differentiation antigen; P53: tumor protein 53, a transcription factor; P63: a P53-related nuclear protein; PAS: periodic acid Schiff stain; PLAP: placenta-like alkaline phosphatase; PR: progesterone receptor; PSA: prostate-specific antigen; RCC: renal cell carcinoma marker; S-100: a neuroectodermal antigen; TTF-1: thyroid transcription factor-1; WT1: Wilms' tumor protein-1 


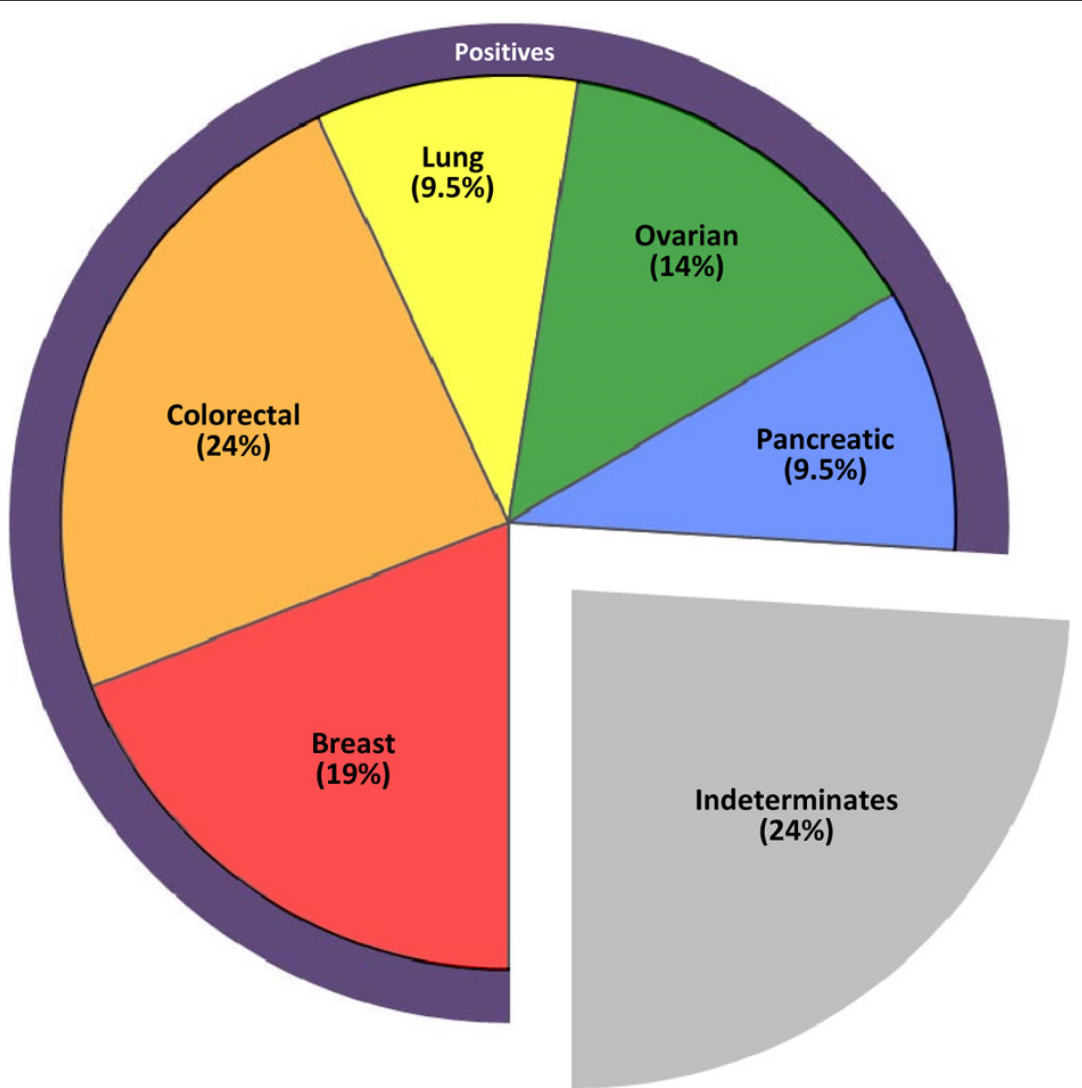

Figure $\mathbf{2}$ Distribution of tumor types in $\mathbf{2 1}$ CUPs. The Tissue of Origin Test called the majority of specimens definitively positive for a single tumor type; in the indeterminate calls, the TOO Test ruled out an average of nine tissue types per specimen.

available at the time of diagnosis was positive, supporting a colorectal origin. On average, the TOO Test ruled out 11 tissue types per case, including in the indeterminate cases. In cases with a positive call, the average number of tissue types ruled out (i.e., SS <5) was 12 while the average in indeterminate calls was 9 .

\section{Discussion}

For patients presenting with uncertain primary tumors and who do not have a primary site identified even after exhaustive investigation empiric chemotherapy is rarely successful and often quite intolerable [7-9]. Better survi$\mathrm{val}$ is achieved when tissue-specific treatment strategies are utilized $[11,12,33]$. Thus, availability of a test that identifies the tissue of origin would increase the chances of a patient receiving a more targeted and less toxic therapy. Depending on how such a test is integrated into the workup of uncertain primaries, it may also reduce the overall time and expense associated with the hunt for a primary tumor. In addition, as new tissue-targeted therapies are expected to be introduced, correct identification of the primary site will become even more important in guiding optimal patient management.
Recently, we reported that the Pathwork Tissue of Origin test showed robust performance in a large validation study with 547 tumors of known origin [29]. We now have evaluated the performance of this test in a cohort of 21 CUP cases. In this cohort the Pathwork TOO Test was able to identify a probable single primary site in $16(76 \%)$ of the cases. These results suggest that the TOO Test can significantly reduce diagnostic uncertainty in patients with CUP.

Three recent studies have reported on gene expression profiling as a strategy to determine TOO in patients with CUP [31-33]. Two of these studies employed a microarray-based 495-gene-expression classifier (CupPrint, Agendia, Amsterdam, NED), which gave a confident and clinically valuable result in 14 (64\%) of 22 CUPs from one study [32] and a clinically feasible result in $18(86 \%)$ of 21 CUPs from the other study [31]. The third study evaluated a 10-gene RT-PCR-based expression assay (Veridex, La Jolla, CA USA) and identified a TOO in $23(62 \%)$ of the 37 specimens classified as CUP after IHC analysis [33]. Thus, expression tests with widely varying designs and features (e.g., number/types of genes; algorithm strategies; training set size; specimen 
handling protocols; number of tissue types on panel) have recently demonstrated an ability to issue a classification for a majority of CUPs.

This general uniformity in call rates for identifying a TOO in CUP patients among the various expression tests (i.e., 62\%-86\%) does not necessarily imply a uniformity of call accuracy or assay range. By definition, the gold standard for tumor calls in CUP cases is unknowable. Thus, accuracy in tissue identification can only be evaluated with the use of a large and diverse set of known tumor specimens. This type of evaluation is needed before any projections can be made about a test's clinical diagnostic value-much less its potential impact on therapy choices and outcome-in the setting of CUP. For example, in one of the studies cited above [32], a parallel analysis of 84 tumors with known origin revealed total assay accuracy of $83 \%$; however, the test misclassified 7 of 11 lung tumors and 3 of 3 pancreas tumors. Thus, if we extrapolate these results to CUP specimens, a large number of CUP tumors with lung or pancreas origin could yield a positive, albeit incorrect, tissue identification. Due to the small number of studied samples (in particular of the lung and pancreas groups) it is not possible to determine the performance of that test for individual tissue types. This same assay showed an accuracy of $87 \%$ in a previous study with 119 tumor samples; however, some tissue types were represented by only one or two specimens (e.g., breast, adrenal) [27]. The 10-gene RT-PCR assay showed an accuracy of $76 \%$ in a set of 48 metastatic samples [26]. Importantly, in a less rigidly defined set of 120 CUP specimens analyzed with the RT-PCR assay [33], this test could not yield a result (due to insufficient mRNA quality or yield) or failed to assign a TOO (perhaps due to a limited 6-tissue panel) in $48 \%$ of the cases. When the Pathwork TOO Test was validated in a large multicenter study $(n=547)$, of poorly differentiated and undifferentiated primary cancers and metastatic tumors, it showed an overall sensitivity (positive percent agreement with reference diagnosis) of $87.8 \%$ for the 15 tissues of origin included in the panel [29]. In this validation study, each of the 15 different tissue sites was represented by at least 25 specimens. These performance characteristics in known tissues must be considered when assessing the likelihood of expression test accuracy in CUP cases.

Our study has several limitations, chief among them the lack of a gold standard for comparison. This inability to confirm accuracy, which is unavoidable in CUP diagnostic studies, only heightens the importance of quality and rigor in the associated clinical and pathological investigations. In this study, patients and CUP specimens were characterized in clinics with extensive experience in oncology workups. Full histories, imaging results, lab records, and pathology reports (including an average of six IHC performed in each case) were available before the CUP diagnosis was issued. Thus, within the inherent constraints of CUP study design, this study provides a fair measure of test performancecertainly at least as fair as any of the seminal validation studies of IHC itself [17-19]. Another limitation of this study was its small size. This is related to the difficulty in finding well-characterized fresh-frozen CUP specimens. Using frozen tissue as a basis for initial CUP performance testing makes sense since it yields more intact mRNA [37]; however, we recognize that it is necessary to validate the TOO Test with formalin-fixed paraffin embedded (FFPE) specimens in order to allow the test to be applied widely in non-research clinical settings.

Given the absence of a gold standard to evaluate CUP assay performance, a surrogate marker of accuracy utilized by prior studies has been the correlation of the TOO prediction with existing clinicopathologic information [31-33,38]. In our study, 10 cases show consistency with the clinicopathologic-based differential diagnosis (Table 2) and in six cases the test's suggested diagnosis was inconsistent. Review of cases where TOO Test positive results were not consistent with IHC and/or tentative clinical suggestions sheds further light on the trustworthiness of gene expression profiles. None of these six TOO Test results were deemed implausible or in absolute contradiction to any known clinicopathologic findings. Even the TOO Test call of breast cancer in a male (Case 18), while surprising, cannot be considered patently incorrect given current estimates of approximately 2000 such new cases in the U.S. every year with a rising incidence [39] and also considering reports of male breast cancer presenting as CUP [40]. In addition, the accompanying TOO Test negative results add weight to the plausibility of surprising positive calls by ruling out several of the originally suspected primaries. In fact, the availability of "rule outs" is a unique feature of TOO Test design that may eventually prove valuable in case management; other tests provide the result of the most molecularly similar tumor but do not report information that allows ruling out specific tissue types. Thus, although six of the TOO Test results were unexpected, given the published performance characteristics of the test and recalling the performance deficits of IHC as cited previously, they were still clinically plausible TOO sites. Based on the overall clinical contributions of TOO Test results, we estimated that the expression test would have helped to inform patient management decisions in the majority of cases (Table 2): definitively in the 16 positive cases by identifying a single primary site, and to varying degrees in the five indeterminate cases by eliminating potential primary sites.

Another measure of the clinical relevance of TOO identification is the ability to evaluate response to therapy in those tumors that were treated with tissue-specific 
approaches. In this regard, Varadhachary and co-workers reported that patients with a molecular signature of colon carcinoma showed better response to colorectalspecific therapies than to empiric CUP therapy [33]. Unfortunately, the size of our study and the unavailability of full outcome and treatment information for all 21 patients make it impossible for us to quantify how the expression results might have translated into changed therapy or improved outcomes. However, review of the treatment data available for about half of the cases indicated that most patients got the type of supportive care with or without empiric chemotherapy that is typical in CUP $[4,7-10]$. Of the 11 Mayo patients, for example, four received at least 4 cycles of chemotherapy and one received radiation therapy (4 radiation sequences, 800 cGy). Many of these patients likely would have received a more tissue-specific therapy if a trusted expression test result had been available at presentation. In Case 11, for example, one of the options for more ovarian-focused chemotherapy might have been given instead of paclitaxel/carboplatin if the TOO Test result of ovarian cancer had been available. In Case 6, doxorubicin and paclitaxel might have been given rather than only supportive care if the TOO Test result supporting a breast origin had been known. Similarly, in Cases 4 and 8, patients might have received bevacizumab instead of a broad-based chemotherapy (paclitaxel/carboplatin with or without gemcitabine) if the TOO Test result indicating colorectal cancer had been available at the time of diagnosis.

Recently, based on retrospective and prospective analyses [12,33], some researchers have already advocated using expression profiles to guide targeted therapy in patients with colorectal cancer profiles. Such changes in CUP therapy directed by molecular profiling might reasonably be expected to equate to improvement in outcomes, but this important hypothesis needs to be tested in prospective studies. Only carefully designed studies will reveal whether tumors originally deemed CUPs respond to specific treatment in the same manner as more well-differentiated tumors of the same tissue type. It may be, for example, that hard-to-identify CUP-like tumors actually possess distinct genetic/phenotypic aberrations (while maintaining tissue-specific expression traits) that limit their susceptibility to therapies tested only in non-CUP tumors [41,42]. In this context, because of the TOO Test's high accuracy in poorly differentiated tumor types and also because of the high number of genes assayed, this test may be particularly well suited not only to classifying tissue origin in CUP but, in the future, to providing information about the tumor's susceptibility to specific therapies.

\section{Conclusions}

The Pathwork TOO Test shows clear promise in identifying tissue origin in cases currently classified as CUP. The test could be a valuable addition or alternative to current diagnostic methods for classifying uncertain primary cancers. Further studies evaluating the impact of gene expression-based test results on therapy choice and treatment outcome for CUP patients are warranted.

\section{Abbreviations}

(CUP): cancer of unknown primary; (TOO): tissue of origin; (IHC): immunohistochemistry; (SS): Similarity Score.

\section{Acknowledgements}

We thank Ted Rigl PhD, Shawn Becker MD, and Raji Pillai PhD for helpful advice, Jenny Liu for assistance in figure preparation and Paul Courter and Jane Seck for writing/editorial support. We thank personnel from the Health Sciences Tissue Bank at the University of Pittsburgh for their assistance in tissue retrieval. This work was supported by Sponsored Research Agreements to Dr. Monzon and Dr. Medeiros from Pathwork Diagnostics Inc.

\section{Author details}

${ }^{1}$ Clinical Genomics Facility, University of Pittsburgh, Pittsburgh, Pennsylvania, USA. ${ }^{2}$ Department of Laboratory Medicine and Pathology, Mayo Clinic, Rochester, Minnesota, USA. ${ }^{3}$ Pathwork Diagnostics, Sunnyvale, California, USA.

\section{Authors' contributions}

FAM participated in the conception, study design, sample identification, results interpretation and correlation with clinical information and manuscript writing. FM participated in the study design, sample identification, results interpretation and correlation with clinical information and manuscript writing. MALW performed all experiments for samples from University of Pittsburgh and performed acquisition and primary analysis of data. WDH participated in the conception, study design, and manuscript preparation. All authors read and approved the final manuscript.

\section{Competing interests}

FAM and FM were recipients of sponsored research agreements from Pathwork Diagnostics for the performance of this study. FAM has received honoraria from Pathwork Diagnostics for speaking engagements related to the Pathwork Tissue of Origin Test. WDH is an employee and stock holder of Pathwork Diagnostics. Pathwork Diagnostics financed writing/editorial assistance and article-processing charges for this manuscript.

Received: 17 December 2009

Accepted: 13 January 2010 Published: 13 January 2010

\section{References}

1. Varadhachary GR, Abbruzzese JL, Lenzi R: Diagnostic strategies for unknown primary cancer. Cancer 2004, 100:1776-1785.

2. Greco FA, Hainsworth JD: Cancer of unknown primary site. Cancer: Principles \& Practice of Oncology Philadelphia: Lippincott Williams \& WilkensDeVita VT, Hellman S, Rosenberg SA , 7 2005, 2213-2234.

3. Pavlidis N, Fizazi K: Carcinoma of unknown primary (CUP). Crit Rev Oncol Hematol 2009, 69:271-278.

4. National Cancer Institute, Carcinoma of Unknown Primary Treatment (PDQ ${ }^{\otimes}$ ) Health Professional Version. http://www.cancer.gov/, Accessed Nov 112008.

5. Jemal A, Siegel R, Ward E, Hao Y, Xu J, Murray T, Thun MJ: Cancer statistics, 2008. CA Cancer J Clin 2008, 58:71-96.

6. Greco FA, Burris HA, Litchy S, Barton JH, Bradof JE, Richards P, Scullin DC Jr, Erland JB, Morrissey LH, Hainsworth JD: Gemcitabine, carboplatin, and paclitaxel for patients with carcinoma of unknown primary site: a Minnie Pearl Cancer Research Network study. J Clin Oncol 2002, 20:1651-1656. 
7. Pavlidis N, Briasoulis E, Hainsworth J, Greco FA: Diagnostic and therapeutic management of cancer of an unknown primary. Eur J Cancer 2003, 39:1990-2005.

8. Hainsworth JD, Spigel DR, Farley C, Thompson DS, Shipley DL, Greco FA, Minnie Pearl Cancer Research Network: Phase II trial of bevacizumab and erlotinib in carcinomas of unknown primary site: the Minnie Pearl Cancer Research Network. J Clin Oncol 2007, 25:1747-1752.

9. Schneider BJ, El-Rayes B, Muler JH, Philip PA, Kalemkerian GP, Griffith KA, Zalupski MM: Phase II trial of carboplatin, gemcitabine, and capecitabine in patients with carcinoma of unknown primary site. Cancer 2007, 110:770-775

10. Pimiento JM, Teso D, Malkan A, Dudrick SJ, Palesty JA: Cancer of unknown primary origin: a decade of experience in a community-based hospital. Am J Surg 2007, 194:833-837.

11. Abbruzzese $J$, Abbruzzese MC, Lenzi R, Hess KR, Raber MN: Analysis of a diagnostic strategy for patients with suspected tumors of unknown origin. J Clin Oncol 1995, 13:2094-2103.

12. Varadhachary GR, Raber MN, Matamoros A, Abbruzzese JL: Carcinoma of unknown primary with a colon-cancer profile-changing paradigm and emerging definitions. Lancet Oncol 2008, 9:596-599.

13. National Comprehensive Cancer Network: NCCN Clinical Practice Guidelines in Oncology, Occult Primary, v.1.2009. http://www.ncen.org/ professionals/physician_gls/PDF/occult.pdf.

14. Pavlidis N, Merrouche $\mathrm{Y}$ : The importance of identifying CUP subsets. Carcinoma of Unknown Primary Site New York, NY: Taylor \& Francis GroupFizazi K 2006, 37-48.

15. Ayoub JP, Hess KR, Abbruzzese MC, Lenzi R, Raber MN, Abbruzzese J Unknown primary tumors metastatic to liver. J Clin Oncol 1998, 16:2105-2112.

16. Voigt JJ, Mathieu MC, Bibeau F: The advent of immunohistochemistry in carcinoma of unknown primary site: a major progress. Carcinoma of Unknown Primary Site New York, NY: Taylor \& Francis GroupFizazi K 2006, 25-35.

17. Brown RW, Campagna LB, Dunn JK, Cagle PT: Immunohistochemical identification of tumor markers in metastatic adenocarcinoma. A diagnostic adjunct in the determination of primary site. Am J Clin Pathol 1997, 107:12-19.

18. Dennis JL, Hvidsten TR, Wit EC, Komorowski J, Bell AK, Downie I, Mooney J, Verbeke C, Bellamy C, Keith WN, Oien KA: Markers of adenocarcinoma characteristic of the site of origin: development of a diagnostic algorithm. Clin Cancer Res 2005, 11:3766-3772.

19. Park SY, Kim BH, Kim JH, Lee S, Kang GH: Panels of immunohistochemical markers help determine primary sites of metastatic adenocarcinoma. Arch Pathol Lab Med 2007, 131:1561-1567.

20. Schapira DV, Jarrett AR: The need to consider survival, outcome, and expense when evaluating and treating patients with unknown primary carcinoma. Arch Intern Med 1995, 155:2050-2054.

21. Ramaswamy $S$, Tamayo $P$, Rifkin R, Mukherjee $S$, Yeang $C H$, Angelo $M$, Ladd C, Reich M, Latulippe E, Mesirov JP, Poggio T, Gerald W, Loda M, Lander ES, Golub TR: Multiclass cancer diagnosis using tumor gene expression signatures. Proc Natl Acad Sci USA 2001, 98:15149-15154.

22. Su Al, Welsh JB, Sapinoso LM, Kern SG, Dimitrov P, Lapp H, Schultz PG, Powell SM, Moskaluk CA, Frierson HF Jr, Hampton GM: Molecular classification of human carcinomas by use of gene expression signatures. Cancer Res 2001, 61:7388-7393.

23. Buckhaults $P$, Zhang Z, Chen YC, Wang TL, St Croix B, Saha S, Bardelli A, Morin PJ, Polyak K, Hruban RH, Velculescu VE, Shih leM: Identifying tumor origin using a gene expression-based classification map. Cancer Res 2003 63:4144-4149.

24. Bloom G, Yang IV, Boulware D, Kwong KY, Coppola D, Eschrich S, Quackenbush J, Yeatman TJ: Multi-platform, multi-site, microarray-based human tumor classification. Am J Pathol 2004, 164:9-16.

25. Tothill RW, Kowalczyk A, Rischin D, Bousioutas A, Haviv I, van Laar RK, Waring PM, Zalcberg J, Ward R, Biankin AV, Sutherland RL, Henshall SM, Fong K, Pollack JR, Bowtell DD, Holloway AJ: An expression-based site of origin diagnostic method designed for clinical application to cancer of unknown origin. Cancer Res 2005, 65:4031-4040.

26. Talantov D, Baden J, Jatkoe T, Hahn K, Yu J, Rajpurohit $Y$, Jiang Y, Choi C, Ross JS, Atkins D, Wang Y, Mazumder A: A quantitative reverse transcriptase-polymerase chain reaction assay to identify metastatic carcinoma tissue of origin. J Mol Diagn 2006, 8:320-329.
27. Ma XJ, Patel R, Wang X, Salunga R, Murage J, Desai R, Tuggle JT, Wang W, Chu S, Stecker K, Raja R, Robin H, Moore M, Baunoch D, Sgroi D, Erlander M: Molecular classification of human cancers using a 92-gene real-time quantitative polymerase chain reaction assay. Arch Pathol Lab Med 2006, 130:465-473.

28. Dumur Cl, Lyons-Weiler M, Sciulli C, Garrett CT, Schrijver I, Holley TK, Rodriguez-Paris J, Pollack JR, Zehnder JL, Price M, Hagenkord JM, Rigl CT, Buturovic LJ, Anderson GG, Monzon FA: Interlaboratory performance of a microarray-based gene expression test to determine tissue of origin in poorly differentiated and undifferentiated cancers. J Mol Diagn 2008, 10:67-77.

29. Monzon FA, Lyons-Weiler M, Buturovic LJ, Rigl CT, Henner WD, Sciulli C, Dumur Cl, Medeiros F, Anderson GG: Multicenter validation of a 1,550gene expression profile for identification of tumor tissue of origin. $J$ Clin Oncol 2009, 27:2503-2508.

30. Rosenfeld N, Aharonov R, Meiri E, Rosenwald S, Spector Y, Zepeniuk M, Benjamin H, Shabes N, Tabak S, Levy A, Lebanony D, Goren $Y$ Silberschein E, Targan N, Ben-Ari A, Gilad S, Sion-Vardy N, Tobar A Feinmesser M, Kharenko O, Nativ O, Nass D, Perelman M, Yosepovich A, Shalmon B, Polak-Charcon S, Fridman E, Avniel A, Bentwich I, Bentwich Z, Cohen D, Chajut A, Barshack I: MicroRNAs accurately identify cancer tissue origin. Nat Biotechnol 2008, 26:462-469.

31. Bridgewater J, van Laar R, Floore A, Van'T Veer L: Gene expression profiling may improve diagnosis in patients with carcinoma of unknown primary. Br J Cancer 2008, 98:1425-1430.

32. Horlings HM, van Laar RK, Kerst JM, Helgason HH, Wesseling J, Hoeven van der JJ, Warmoes MO, Floore A, Witteveen A, Lahti-Domenici J, Glas AM, Van't Veer $L J$, de Jong D: Gene expression profiling to identify the histogenetic origin of metastatic adenocarcinomas of unknown primary. J Clin Oncol 2008, 26:4435-4441.

33. Varadhachary GR, Talantov D, Raber MN, Meng C, Hess KR, Jatkoe T, Lenzi R, Spigel DR, Wang Y, Greco FA, Abbruzzese JL, Hainsworth JD: Molecular profiling of carcinoma of unknown primary and correlation with clinical evaluation. J Clin Oncol 2008, 26:4442-4428.

34. Moraleda J, Grove N, Tran Q: Gene expression data analytics with interlaboratory validation for identifying anatomical sites of origin of metastatic carcinomas. J Clin Oncol 2004, 22(July 15 suppl):abstr 9625.

35. Yamamoto J, Ohshima K, Nabeshima K, Ikeda S, Iwasaki H, Kikuchi M: Comparative study of primary mammary small cell carcinoma, carcinoma with endocrine features and invasive ductal carcinoma. Oncol Rep 2004, 11:825-831.

36. Compérat E, Zhang F, Perrotin C, Molina T, Magdeleinat P, Marmey B, Régnard JF, Audouin J, Camilleri-Broët S: Variable sensitivity and specificity of TTF-1 antibodies in lung metastatic adenocarcinoma of colorectal origin. Mod Pathol 2005, 18:1371-1376.

37. Medeiros F, Rigl CT, Anderson GG, Becker SH, Halling KC: Tissue handling for genome-wide expression analysis: a review of the issues, evidence, and opportunities. Arch Pathol Lab Med 2007, 131:1805-1816.

38. Oien KA, Evans TR: Raising the profile of cancer of unknown primary. J Clin Oncol 2008, 26:4373-4375.

39. Nahleh ZA, Srikantiah R, Safa M, Jazieh AR, Muhleman A, Komrokji R: Male breast cancer in the veterans affairs population: a comparative analysis. Cancer 2007, 109:1471-1477.

40. Spencer JT, Shutter J: Synchronous bilateral invasive lobular breast cancer presenting as carcinomatosis in a male. Am J Surg Pathol 2009, 33:470-474.

41. Pentheroudakis $\mathrm{G}$, Briasoulis $\mathrm{E}$, Pavlidis N: Cancer of unknown primary site: missing primary or missing biology?. The Oncologist 2007, 12:418-425.

42. Pentheroudakis G, Greco FA, Pavlidis N: Molecular assignment of tissue of origin in cancer of unknown primary may not predict response to therapy or outcome: A systematic literature review. Cancer Treat Rev 2009, 35:221-227.

doi:10.1186/1746-1596-5-3

Cite this article as: Monzon et al:: Identification of tissue of origin in carcinoma of unknown primary with a microarray-based gene expression test. Diagnostic Pathology 2010 5:3. 